\title{
An Integrated Picture Fuzzy Set with TOPSIS-AHP Approach to Group Decision-Making in Policymaking under Uncertainty
}

\author{
Long Cu Kim \\ School of Information and Communication Technology, \\ Hanoi University of Science and Technology, \\ No. 1, Dai Co Viet Rd, Hai Ba Trung, Hanoi, Vietnam. \\ E-mail: long.ckncs18023@ sis.hust.edu.vn

\section{Hai Pham Van} \\ School of Information and Communication Technology, \\ Hanoi University of Science and Technology, \\ No. 1, Dai Co Viet Rd, Hai Ba Trung, Hanoi, Vietnam. \\ Corresponding author: haipv@ soict.hust.edu.vn
}

(Received on June 15, 2021; Accepted on October 19, 2021)

\begin{abstract}
Group Decision-Making techniques have been applied to combine a group of decision maker's preferences to deal with an evaluation of alternatives in a static environment. However, these conventional techniques are only concerned with an evaluation in a static environment. They cannot solve the policy evaluation problems in a dynamic environment or under uncertainty. This paper has presented a novel proposed model to handle the policy evaluation problems under uncertainty by integrating the Picture fuzzy set with the traditional TOPSIS-AHP model. The qualitative and quantitative factors are been quantified by using Picture fuzzy set to evaluate alternatives in order to make complex decisions in a dynamic environment. To validate the proposed model, a numerical example was illustrated meticulously. The experimental results also proved that the proposed method based on the indicator groups in the final urban development project in Vietnam combined with the expert's expertise and the decision-maker's preference gives the more confident evaluation result compared to the state-of-the-art works by applying the fuzzy decision point of the policy.
\end{abstract}

Keywords- Fuzzy, Picture fuzzy set, TOPSIS, AHP, GDM, Policymaking.

\section{Introduction}

Policymaking is one of three steps (promulgation, implementation organization, and evaluation) in policy cycles (Kaya et al., 2019; Munro and Cairney, 2020). It is a policy designing process to meet societies real needs. Policymaking is an extremely important task because the new policy draft is built whether it is agreed on by concerning agencies as well as citizens or businesses? After promulgating, does the new policy get support from people or businesses? How to apply the new policy effectively? Therefore, policymaking must focus on making decisions, especially base on the high priority decision (Pluchinotta et al., 2019; Long et al., 2021). A conventional Group DecisionMaking (GDM) model is commonly known as collaborative decision-making when decision-makers give the right decisions in the evaluation of alternatives (de Farias Aires and Ferreira, 2019; Salih et al., 2019). GDM can be used to combine experts' preferences to solve complicated problems (Philip and Hai, 2012). The TOPSIS and AHP model are considered the very strong traditional techniques for GDM to support the multi-criteria evaluation problems. Hai and Esichaikul (2008), Akram et al. (2021) combined these techniques to propose the TOPSIS-AHP model to evaluate lecturers based on the ICT Newhouse Factors. Zaidan et al. (2015) and Kahraman et al. (2018) have also proposed the integrated AHP-TOPSIS model for software selection using multi-criteria decision-making. These 
methods have demonstrated the effectiveness of the lecture evaluation based on multi-criteria with the many experts attending. Though, these methods could not solve the quantifying issues when input data contain the linguistic values.

Recently, the direction of the multi-criteria decision-making approach based on fuzzy techniques has received much attention from the researcher community around the world. For example, the fuzzy AHP method is introduced in many works (Kara, 2019; Liu et al., 2020; Salimi and Edalatpanah, 2020), the picture fuzzy set-based decision-making approach is given in studies (Cuong, 2014; Son et al., 2016; Tang and Liao, 2019; Khan et al., 2020; Lan et al., 2020; Garg et al., 2021; Si et al., 2021; Sirbiladze, 2021), the fuzzy AHP multi-criteria analysis and mathematical model for the evaluation of availability based on expert judgment is presented in works by Djenadic et al. (2019) and Edalatpanah (2020). However, the main limitation in the state-of-the-art works shows that they have not still handled the evaluation problems in real life when the input information of the attributes contains vague values. For instance, in relevant examples of real-world problems in terms of policymaking, suppose that the e-government strategy is evaluated by 300 voters who participate in the voting process. The results show that 150 voters agree on the government strategy, 80 voters abstain from the voting process, 40 voters disagree on the strategy, and 30 voters refuse selection. Their voting scales can be divided into four types, namely, vote for, abstain, vote against, and refuse the voting government strategy. Besides, these investigations have only been assessed in a static environment, while decision maker's preferences, using GDM, can be divided into scales such as the positive, negative, neutral, and refusal degree of the voting scales in the evaluation of alternatives. Furthermore, most of the research mainly focused on other sectors' evaluation problems but bit attention to the policymaking problems.

Motivated by the mentioned limitations, this paper proposes a novel multi-criteria evaluation model by integrating the picture fuzzy set technique into the traditional models (e.g., TOPSIS-AHP, Fuzzy TOPSIS, Fuzzy AHP), the so-called PFS-TOPSIS-AHP model. The proposed model has the outperformed advantages compared to the other state-of-the-art models in terms of policy evaluation in a dynamic environment and in recommending the confidence of the new policy by using the fuzzy decision point. These help the evaluation result to emphasize the positive, neutral, negative, or refusal degrees of the new policies under uncertainty. The key contributions of this paper are given in Figure 1, namely:

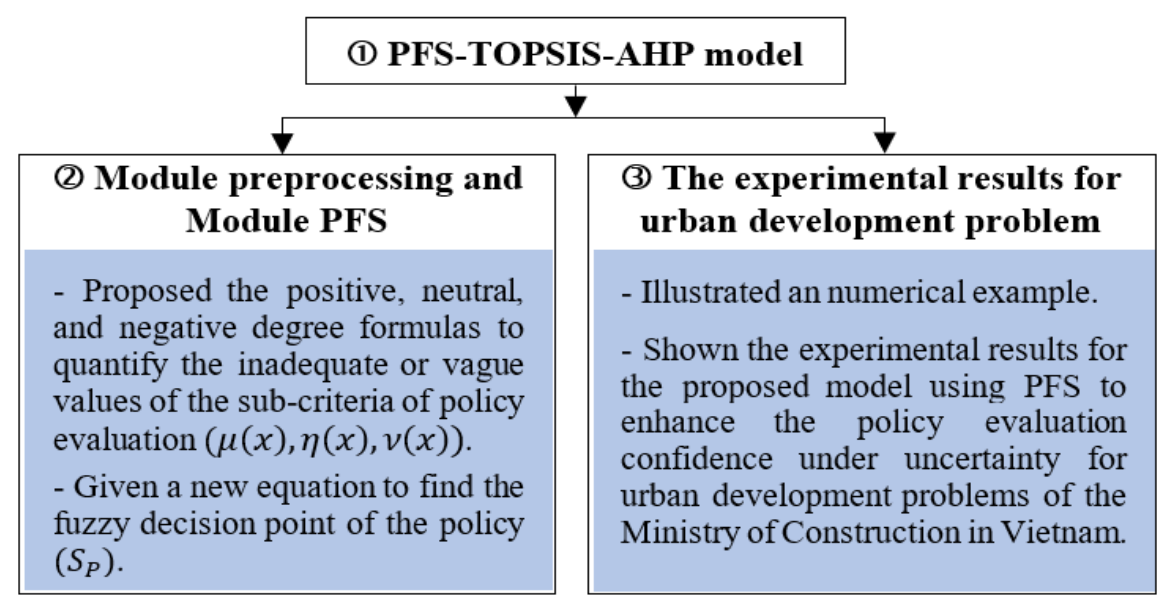

Figure 1. The key contributions of the paper. 
Firstly, the novel PFS-TOPSIS-AHP model is proposed to evaluate policymaking under uncertainty. This proposed model has quantified both qualitative and quantitative factors to evaluate the policies to make complex decisions under uncertainty.

Secondly, the PFS technique is integrated successfully into the TOPSIS-AHP model to solve the limitations in the state-of-the-art investigations. The detailed contributions are shown in the light blue highlighted steps of the evaluation phase in Figure 1.

- The positive, neutral, and negative degree formulas are proposed to quantify the inadequate or vague values for the policy evaluation problems at Step 5 (Module preprocessing data from experts).

- In addition, a new formula is given to find the fuzzy decision point to recommend the confidence of the policy at Step 7 (Module PFS for evaluating policy's confidence).

Finally, to validate the proposed model, a numerical example is presented meticulously. The experimental results also illustrate the proposed model using PFS to enhance the policy evaluation confidence under uncertainty for urban development problems of the Ministry of Construction in Vietnam.

The remaining of this paper is structured as follows. Section 2 presents the basic concepts related to GDM, fuzzy, and picture fuzzy sets. The problem statement and proposed model are given in Section 3. Section 4 shows a numerical example to demonstrate the proposed model. Additionally, Section 5 describes experimental results for a case study of building urban database development, applied the proposed model. The conclusion and further works are delineated in the last section.

\section{Preliminaries}

\subsection{Fuzzy Set}

Definition 1. A fuzzy set (FS) (Zadeh L.A., 1965) $A$ on a universe $X$ is an object of the form $A=$ $\left\{\left\langle x, \mu_{A}(x)\right\rangle \mid \forall x \in X, \mu_{A}(x) \in[0,1]\right\}$ where $\mu_{A}(x)$ is called the degree of membership of $x$ in $A$.

\subsection{Picture Fuzzy Set}

Definition 2. A picture fuzzy set (Cuong, 2014) is a non-empty set $X$ is $A=$ $\left\{\left(x, \mu_{A}(x), \eta_{A}(x), v_{A}(x)\right) \mid x \in X\right\}$, where $\mu_{A}(x) \in[0,1]$ is the positive degree of each element $x \in$ $X, \eta_{A}(x) \in[0,1]$ is the neutral degree and $v_{A}(x) \in[0,1]$ is the negative degree, and where $\mu_{A}, \eta_{A}$ and $v_{A}$ satisfy the following conditions: $(\forall x \in X) \quad\left(\mu_{A}(x)+\eta_{A}(x)+v_{A}(x) \leq 1\right)$, and $\xi_{A}(x)=$ $1-\left(\mu_{A}(x)+\eta_{A}(x)+v_{A}(x)\right)$ is the refusal degree of an element $x \in X$. Let PFS $(X)$ denote the set of all the PFSs on a universe $X$.

\subsection{Formulation and Problem in GDM to PFS}

Let $\boldsymbol{X}$ be a set of alternatives $\boldsymbol{X}=\left\{X_{1}, \ldots, X_{n}\right\}$. Let a PFS $\boldsymbol{E}=\left\{e\left(X_{1}\right), \ldots, e\left(X_{n}\right)\right\}$ on $\boldsymbol{X}$, where $e\left(X_{i}\right)=\left(\mu\left(X_{i}\right), \eta\left(X_{i}\right), v\left(X_{i}\right)\right), 0 \leq \mu\left(X_{i}\right), \eta\left(X_{i}\right), v\left(X_{i}\right) \leq 1$, and $\mu\left(X_{i}\right)+\eta\left(X_{i}\right)+v\left(X_{i}\right) \leq$ $1, \forall i$. The GDM problem is to rank the set of alternatives and to select the best alternative. Several steps are ordered as follows.

Firstly, score functions are defined on $\boldsymbol{X} f_{1}\left(X_{i}\right)=\mu\left(X_{i}\right) ; f_{2}\left(X_{i}\right)=\eta\left(X_{i}\right) ; f_{3}\left(X_{i}\right)=\mu\left(X_{i}\right)+$ $\eta\left(X_{i}\right)-v\left(X_{i}\right), \forall i$. Then, define order $\gtrsim_{1}$ on $\boldsymbol{X}$ by using $X_{i} \gtrsim_{1} X_{k}$ iff $f_{1}\left(X_{i}\right) \geq f_{1}\left(X_{k}\right)$; define order $\gtrsim_{2}$ on $\boldsymbol{X}$ by using $X_{i} \gtrsim_{2} X_{k}$ iff $f_{2}\left(X_{i}\right) \geq f_{2}\left(X_{k}\right)$; define order $\gtrsim_{3}$ on $\boldsymbol{X}$ by using 
$X_{i} \gtrsim_{3} X_{k}$ iff $f_{3}\left(X_{i}\right) \geq f_{3}\left(X_{k}\right)$. Finally, define on $\boldsymbol{X}$ aggregation order $\gtrsim_{*}$ by using $\gtrsim_{1}, \gtrsim_{2}, \gtrsim_{3}$, then rank the set of alternatives and select the best alternative.

\section{The Proposed Method}

This section presents some key contents for illustrating the proposed method, such as a problem statement and a novel proposed model for evaluating the new policymaking under uncertainty.

\subsection{The Problem Statements}

By using GDM, the general problem is given in this subsection that describes the detailed input and output. The evaluation result can be applied to help decision-makers in several domains (such as construction, science and technology, and so on).

Input: Suppose that we have the below list of the new proposed policies in Table 1 after gathering data from a set of evaluating experts $E=\left\{E_{1}, E_{2}, E_{3}, \ldots, E_{m}\right\}$, based on a set of the criteria $C=$ $\left\{C_{1}, C_{2}, C_{3}, \ldots, C_{n}\right\}$. Each criterion set $\left(C_{i}\right)$ can have one or more sub-criteria. The value of subcriteria $\left(c_{i j}\right)$ can be a digit or linguistic value. A set of the proposed policies $P=$ $\left\{P_{1}, P_{2}, P_{3}, \ldots, P_{k}\right\}$ needs to be evaluated before the policy-maker gives a final decision to approve a new policy.

Table 1. List of the policies for evaluation.

\begin{tabular}{|c|c|c|c|c|c|c|}
\hline Criteria & Policies & $\boldsymbol{E}_{\mathbf{1}}$ & $\boldsymbol{E}_{\mathbf{2}}$ & $\boldsymbol{E}_{\mathbf{3}}$ & $\cdots$ & $\boldsymbol{E}_{\boldsymbol{m}}$ \\
\hline \multirow{4}{*}{$\boldsymbol{C}_{\mathbf{1}}$} & $P_{1}$ & $\left\{c_{11}, c_{12}, \cdots, c_{1 s}\right\}$ & $\left\{c_{11}, c_{12}, \cdots, c_{1 s}\right\}$ & $\left\{c_{11}, c_{12}, \cdots, c_{1 s}\right\}$ & $\cdots$ & $\left\{c_{11}, c_{12}, \cdots, c_{1 s}\right\}$ \\
\cline { 2 - 7 } & $\cdots$ & $\left\{c_{11}, c_{12}, \cdots, c_{1 s}\right\}$ & $\left\{c_{11}, c_{12}, \cdots, c_{1 s}\right\}$ & $\left\{c_{11}, c_{12}, \cdots, c_{1 s}\right\}$ & $\cdots$ & $\left\{c_{11}, c_{12}, \cdots, c_{1 s}\right\}$ \\
\cline { 2 - 7 } & $P_{\boldsymbol{k}}$ & $\left\{c_{11}, c_{12}, \cdots, c_{1 s}\right\}$ & $\left\{c_{11}, c_{12}, \cdots, c_{1 s}\right\}$ & $\left\{c_{11}, c_{12}, \cdots, c_{1 s}\right\}$ & $\cdots$ & $\left\{c_{11}, c_{12}, \cdots, c_{1 s}\right\}$ \\
\hline \multirow{3}{*}{$\boldsymbol{C}_{\mathbf{2}}$} & $P_{1}$ & $\left\{c_{21}, c_{22}, \cdots, c_{2 t}\right\}$ & $\left\{c_{21}, c_{22}, \cdots, c_{2 t}\right\}$ & $\left\{c_{21}, c_{22}, \cdots, c_{2 t}\right\}$ & $\cdots$ & $\left\{c_{21}, c_{22}, \cdots, c_{2 t}\right\}$ \\
\cline { 2 - 7 } & $\cdots$ & $\left\{c_{21}, c_{22}, \cdots, c_{2 t}\right\}$ & $\left\{c_{21}, c_{22}, \cdots, c_{2 t}\right\}$ & $\left\{c_{21}, c_{22}, \cdots, c_{2 t}\right\}$ & $\cdots$ & $\left\{c_{21}, c_{22}, \cdots, c_{2 t}\right\}$ \\
\cline { 2 - 7 } & $P_{\boldsymbol{y y y y y y}}$ & $\left\{c_{21}, c_{22}, \cdots, c_{2 t}\right\}$ & $\left\{c_{21}, c_{22}, \cdots, c_{2 t}\right\}$ & $\left\{c_{21}, c_{22}, \cdots, c_{2 t}\right\}$ & $\cdots$ & $\left\{c_{21}, c_{22}, \cdots, c_{2 t}\right\}$ \\
\hline \multirow{3}{*}{$\boldsymbol{C}_{\boldsymbol{n}}$} & $\vdots$ & $\vdots$ & $\vdots$ & $\vdots$ & $\cdots$ & $\vdots$ \\
\cline { 2 - 8 } & $P_{1}$ & $\left\{c_{m 1}, c_{m 2}, \cdots, c_{m v}\right\}$ & $\left\{c_{m 1}, c_{m 2}, \cdots, c_{m v}\right\}$ & $\left\{c_{m 1}, c_{m 2}, \cdots, c_{m v}\right\}$ & $\cdots$ & $\left\{c_{m 1}, c_{m 2}, \cdots, c_{m v}\right\}$ \\
\cline { 2 - 7 } & $\cdots$ & $\left\{c_{m 1}, c_{m 2}, \cdots, c_{m v}\right\}$ & $\left\{c_{m 1}, c_{m 2}, \cdots, c_{m v}\right\}$ & $\left\{c_{m 1}, c_{m 2}, \cdots, c_{m v}\right\}$ & $\cdots$ & $\left\{c_{m 1}, c_{m 2}, \cdots, c_{m v}\right\}$ \\
\cline { 2 - 7 } & $P_{k}$ & $\left\{c_{m 1}, c_{m 2}, \cdots, c_{m v}\right\}$ & $\left\{c_{m 1}, c_{m 2}, \cdots, c_{m v}\right\}$ & $\left\{c_{m 1}, c_{m 2}, \cdots, c_{m v}\right\}$ & $\cdots$ & $\left\{c_{m 1}, c_{m 2}, \cdots, c_{m v}\right\}$ \\
\hline
\end{tabular}

Output: The evaluation result for each proposed policy.

To handle the above problem, a new method is proposed in this work to evaluate the proposed policies in an uncertain environment. This helps the decision-maker who can give the final decision accurately before promulgating a new policy. In the next part, we present a novel model for applying to evaluate policymaking under uncertainty.

\subsection{The Proposed Model}

This part gives a novel proposed model to evaluate the policies (so-called PFS-TOPSIS-AHP model) that is illustrated in Figure 2. It includes ten steps divided into three phases (preparation phase, evaluation phase, and decision phase). 


\subsubsection{Preparation Phase}

This phase is described as follows: First of all, the criteria and the sub-criteria (if have) need to be identified before conducting the evaluation of the policies. This is a very important step not only in the proposed method but also in the traditional method as well as in the state-of-the-art method. Then, the rating scale of the criteria and the policies are given to gain the consensus among experts during gathering data and evaluating the policies. This step helps also to quantify the criteria's value in case the surveying data includes linguistic or vague values. Finally, the evaluating data is collected from experts by surveying and is stored in the database. The results of this phase are used as the input data for the evaluation phase in the next part.

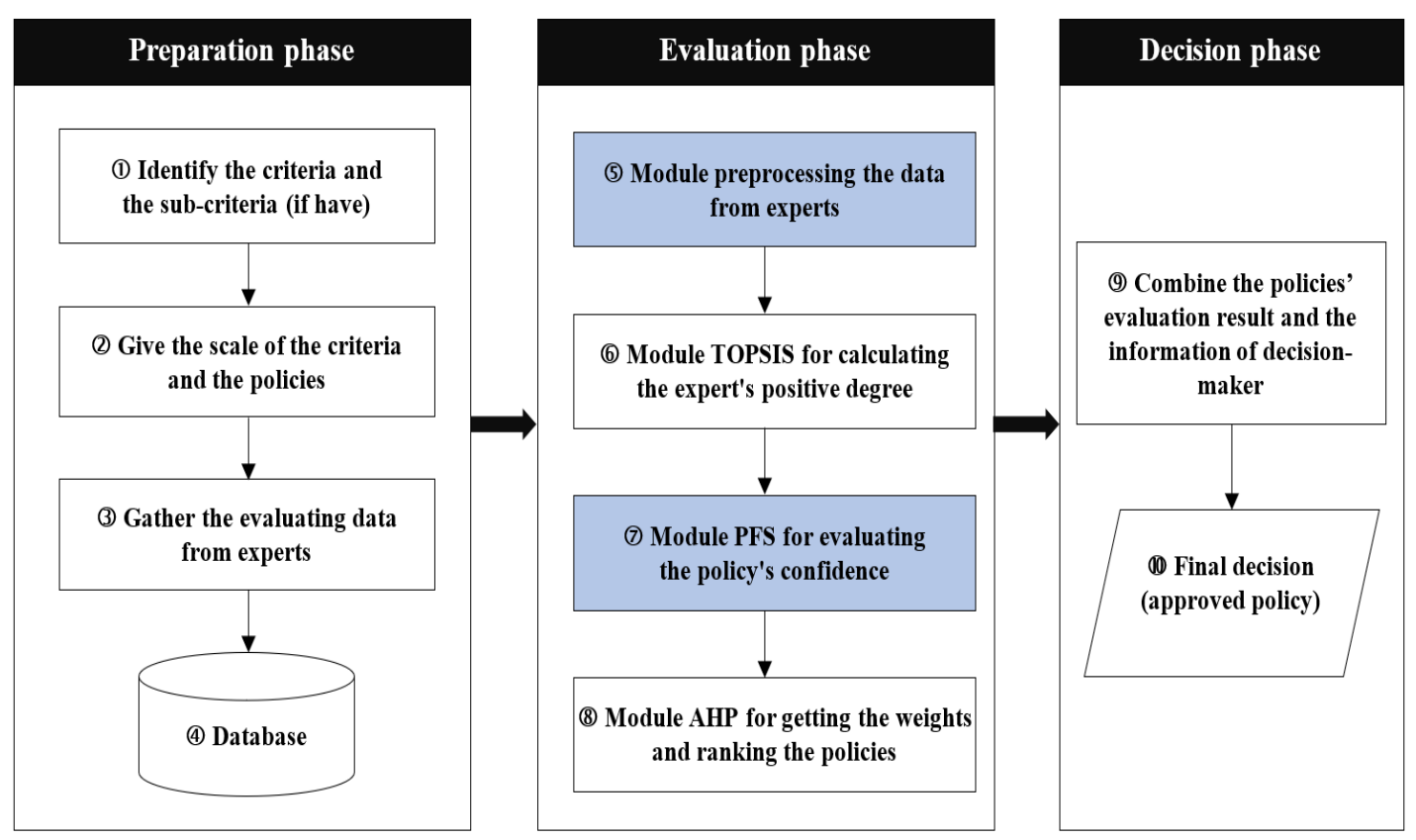

Figure 2. A novel PFS-TOPSIS-AHP model for evaluating policymaking under uncertainty.

\subsubsection{Evaluation Phase}

The evaluation phase is considered a core part of the proposed model. To easily and logically understand the integration of picture fuzzy set (PFS) into the TOPSIS-AHP, the calculation process in this phase is presented step by step as follows.

Step 1. Apply the data pre-processing module.

After collecting the data from the surveying process, the data pre-processing module is applied to quantify the ambiguous data. In case, the value of the criteria is digits, we move the module TOPSIS in Step 2. In other cases, the fuzzy technique is used to quantify the value of the criteria (e.g., linguistic or vague values). The output of this step is shown in Table 1.

Step 2. Calculate the criteria weights and rank the expert's positive degree. 
Step 2.1 Construct a decision matrix based on input data. From data in Table 1, we construct a decision matrix by applying Equation (1) below.

$M=\left[\begin{array}{cccc}c_{11} & c_{12} & & c_{1 n} \\ c_{21} & c_{22} & \cdots & c_{2 n} \\ & \vdots & \ddots & \vdots \\ c_{m 1} & c_{m 2} & \cdots & c_{m n}\end{array}\right]$

Step 2.2 Construct the normalized decision matrix. A standard matrix is given by using Equations (2) and (3) as follows.

$r_{i j}=\frac{c_{i j}}{\sqrt{\sum_{i=1}^{m} c_{i j}^{2}}}$

$M^{\prime}=\left[\begin{array}{cccc}r_{11} & r_{12} & & r_{1 n} \\ r_{21} & r_{22} & \cdots & r_{2 n} \\ & \vdots & \ddots & \vdots \\ r_{m 1} & r_{m 2} & \cdots & r_{m n}\end{array}\right]$

where, $1 \leq i \leq m, 1 \leq j \leq n$.

Step 2.3 Find the set of weights for criteria by using Entropy. by applying Equation (4) to calculate the set of weights $a=\left\{a_{1}, a_{2}, \ldots, a_{n}\right\}$ for criteria.

$E_{j}=-\frac{1}{\ln m} \sum_{i=1}^{m} r_{i j} \ln r_{i j} ; G_{j}=1-E_{j} ; a_{j}=\frac{G_{j}}{\sum_{j=1}^{n} G_{j}}$

where, $1 \leq i \leq m, 1 \leq j \leq n$.

Step 2.4 Establish the weighted normalized decision matrix by applying Equation (5).

$M^{*}=\left[\begin{array}{cccc}a_{1} r_{11} & a_{2} r_{12} & & a_{n} r_{1 n} \\ a_{1} r_{21} & a_{2} r_{22} & \cdots & a_{n} r_{2 n} \\ & \vdots & \ddots & \vdots \\ a_{1} r_{m 1} & a_{2} r_{m 2} & \cdots & a_{n} r_{m n}\end{array}\right]=\left[\begin{array}{cccc}v_{11} & v_{12} & & v_{1 n} \\ v_{21} & v_{22} & \cdots & v_{2 n} \\ & \vdots & \ddots & \vdots \\ v_{m 1} & v_{m 2} & \cdots & v_{m n}\end{array}\right]$

Step 2.5 Find vector pairs PIS (Positive Ideal Solution) and NIS (Negative Ideal Solution) given by Equations (6) and (7) respectively.

$A^{*}=\left\{v_{1}^{*}, v_{2}^{*}, \ldots, v_{n}^{*}\right\}$ where $v_{j}^{*}=\operatorname{Max}_{i=1 \rightarrow m}\left\{v_{i j}\right\}$

$A^{-}=\left\{v_{1}^{-}, v_{2}^{-}, \ldots, v_{n}^{-}\right\}$where $v_{j}^{-}=\operatorname{Min}_{i=1 \rightarrow m}\left\{v_{i j}\right\}$

Step 2.6 Calculate the distance to ideal solutions based on Euclidean distance formula given by Equations (8) and (9) respectively.

$S_{i}^{*}=\sqrt{\sum_{j=1}^{n}\left(v_{i j}-v_{j}^{*}\right)^{2}}$ where, $1 \leq i \leq m$.

$S_{i}^{-}=\sqrt{\sum_{j=1}^{n}\left(v_{i j}-v_{j}^{-}\right)^{2}}$ where, $1 \leq i \leq m$. 
Step 2.7 Calculate the positive degree of the experts, expressed by Equation (10).

$C=\left\{C_{1}^{*}, C_{2}^{*}, \ldots, C_{m}^{*} \mid C_{i}^{*}=\frac{\sum s_{i}^{-}}{\sum s_{i}^{-}+\sum s_{i}^{*}}, 1 \leq i \leq m\right\}$

Step 2.8 Rank the expert's positive degree according to the results at Step 2.7.

In case, the criteria have some sub-criteria, the output result with the sub-criteria will be gotten as the input of the criteria of Step 2. Furthermore, they are used to find the set of weights for criteria as well as the set of weights for experts in Step 3.

Step 3. Find the set of weights for experts by using fuzzy AHP. After ranking the expert's positive degree in Step 2, the AHP technique is applied to find the set of the criteria's weights $w_{c}=$ $\left\{w_{1}, w_{2}, \cdots, w_{n}\right\}$. The level of the criteria's importance is converted by using Equation (11).

$\omega_{i j}=\frac{x_{i}}{x_{j}}$

where, $x_{i}, x_{j}$ are value of the criteria $C_{i}, C_{j}$.

Next, the compared matrix among the importance levels for each criterion is established to find the eigenvectors of each criteria set. Thereafter, we calculate the set of the expert's weights

$$
w_{E}=\left\{w_{1}, w_{2}, \cdots, w_{m}\right\} \text {. }
$$

Step 4. Find the criteria's PFS and calculate the fuzzy decision point of the policies.

Step 4.1 Give the PFS represents the positive degree of the policy. The PFS represents the positive degree of the policy given by Equation (12) as follows.

$\mathrm{P}=\{(x, \mu(x), \eta(x), v(x)) \mid x \in[1,9]\}$

where,

$$
\begin{aligned}
& \mu(x)=\left\{\begin{array}{lr}
0 & \text { iff } x \leq 5 \\
\frac{x-5}{9-5} & \text { iff } 5<x \leq 9
\end{array}\right. \\
& \eta(x)=\left\{\begin{array}{lr}
0 & \text { iff } x \geq 7 \\
\frac{7-x}{7-5} & \text { iff } 5 \leq x<7 \\
\frac{x-3}{5-3} & \text { iff } 3<x<5 \\
0 & \text { iff } x \leq 3
\end{array}\right. \\
& \nu(x)=\left\{\begin{array}{lr}
0 & \text { iff } x \geq 5 \\
\frac{5-x}{5-1} & \text { iff } 1 \leq x<5
\end{array}\right.
\end{aligned}
$$

Step 4.2 Find the fuzzy decision point of the policy with the sub-criteria, the value of the positive degree, the neutral degree, and negative degree is given by Equation (16).

$\mu(x)=\frac{\sum_{i=1}^{n} \mu\left(x_{i}\right)}{n}, \eta(x)=\frac{\sum_{i=1}^{n} \eta\left(x_{i}\right)}{n}, v(x)=\frac{\sum_{i=1}^{n} v\left(x_{i}\right)}{n}$

For the criteria $\left\{C_{1}, C_{2}, C_{3}, \ldots, C_{n}\right\}$ with $w_{c}=\left\{w_{1}, w_{2}, \cdots, w_{n}\right\}$, we have:

$\mu(x)=\sum_{i=1}^{n} w_{i} \mu\left(x_{i}\right), \eta(x)=\sum_{i=1}^{n} w_{i} \eta\left(x_{i}\right), v(x)=\sum_{i=1}^{n} w_{i} v\left(x_{i}\right)$ 
After calculating the final PFS, we get the fuzzy decision point of the policy by applying the function $S_{P}$ given by Equation (18).

$S_{P}=\mu(x)+(\mu(x)-v(x)) *(1-\mu(x)-\eta(x)-v(x))-v(x)$

\subsubsection{Decision Phase}

Base on the rating scale, the fuzzy decision point of the policy $\left(S_{\mathrm{P}}\right)$ shows the quality of the proposed policy that is one of the results such as "Very Good", "Good", "Quite Good", "Normal", or "Bad". According to the evaluation result, the decision-maker combines the calculating result of the PFS-TOPSIS-AHP model and his/her available information to give the final decision. The new policy will be only promulgated by the decision-maker when the evaluation result of the policy must gain "Quite Good" at least. To clearly crisp the proposed method, an illustrative example is presented in Part 4.

\section{The Illustrative Example}

To validate the PFS-TOPSIS-AHP model, a numerical example is illustrated in this part. Suppose that we have a new proposed policy about the urbanization problem of the cities in Table 2 after gathering data from three experts $\left\{E_{1}, E_{2}, E_{3}\right\}$, base on six criteria sets $\left\{C_{1}, C_{2}, C_{3}, \ldots, C_{6}\right\}$. Each criterion set $\left(C_{i}\right)$ has some sub-criteria $\left(c_{i j}\right)$. The new proposed policy needs to be evaluated based on the rating scale of the policy given in Table 3 before giving a final decision by the decisionmaker. Besides, the scale of the criteria set importance is also given in Table 4.

Now, we use the proposed method to solve this problem step by step as follows.

Table 2. The gathering of data from evaluation experts for criteria.

\begin{tabular}{|c|c|c|c|}
\hline & Expert $1\left(E_{1}\right)$ & Expert $2\left(E_{2}\right)$ & $\operatorname{Expert} 3\left(E_{3}\right)$ \\
\hline Criteria set $1\left(\mathrm{C}_{1}\right)$ & $\{3,5,7,9,6,5,6\}$ & $\{2,5,8,6,9,3,8\}$ & $\{6,7,9,8,5,9,8\}$ \\
\hline Criteria set $2\left(\mathrm{C}_{2}\right)$ & $\{3,5,7,9\}$ & $\{3,6,5,5\}$ & $\{2,7,3,9\}$ \\
\hline Criteria set $3\left(\mathrm{C}_{3}\right)$ & $\{5,6,3,8,2\}$ & $\{6,8,9,5,8\}$ & $\{3,4,7,8,6\}$ \\
\hline Criteria set $4\left(\mathrm{C}_{4}\right)$ & $\{6,3,5,7,9,6,2\}$ & $\{7,5,2,7,5,6,5\}$ & $\{8,9,9,7,8,8,6\}$ \\
\hline Criteria set $5\left(\mathrm{C}_{5}\right)$ & $\{7,7,9,7,5\}$ & $\{9,9,3,7,5\}$ & $\{9,4,9,7,5\}$ \\
\hline Criteria set $6\left(\mathrm{C}_{6}\right)$ & $\{6,9,5,7\}$ & $\{6,8,5,7\}$ & $\{5,7,6,4\}$ \\
\hline
\end{tabular}

Table 3. The rating scale of the policy's quality.

\begin{tabular}{|c|c|c|c|}
\hline Level & Notation & Value & Meaning \\
\hline Very Good & $\mathrm{M}_{1}$ & 9 & The best quality policy evaluation \\
\hline Good & $\mathrm{M}_{2}$ & 7 & The good quality policy evaluation \\
\hline Quite Good & $\mathrm{M}_{3}$ & 5 & The pretty quality policy evaluation \\
\hline Normal & $\mathrm{M}_{4}$ & 3 & The moderate quality policy evaluation \\
\hline Bad & $\mathrm{M}_{5}$ & 1 & The bad quality policy evaluation \\
\hline
\end{tabular}

Table 4. The scale of the criteria set importance.

\begin{tabular}{|c|c|c|}
\hline Level & Value & Reciprocal Value \\
\hline Extreme importance & 9 & 0.1111 \\
\hline Very strong to extreme importance & 8 & 0.1250 \\
\hline Very strong importance & 7 & 0.1429 \\
\hline Strong to very strong importance & 6 & 0.1667 \\
\hline Strong importance & 5 & 0.2000 \\
\hline Moderate to strong importance & 4 & 0.2500 \\
\hline Moderate importance & 3 & 0.3333 \\
\hline Equal to moderate importance & 2 & 0.5000 \\
\hline Equal importance & 1 & 1.0000 \\
\hline
\end{tabular}


Step 1. Establish a decision matrix based on input data for the criteria sets from the data in Table 2 , we construct a decision matrix for the criteria set $\left(\mathrm{C}_{1}\right)$ in Table 5 as follows.

Table 5. The decision matrix for the criteria set $\left(\mathrm{C}_{1}\right)$.

\begin{tabular}{|c|c|c|c|c|c|c|c|}
\hline & $\mathbf{C}_{\mathbf{1 1}}$ & $\mathbf{C}_{\mathbf{1 2}}$ & $\mathbf{C}_{\mathbf{1 3}}$ & $\mathbf{C}_{\mathbf{1 4}}$ & $\mathbf{C}_{\mathbf{1 5}}$ & $\mathbf{C}_{\mathbf{1 6}}$ & $\mathbf{C}_{\mathbf{1 7}}$ \\
\hline $\mathbf{E}_{\mathbf{1}}$ & 3 & 5 & 7 & 9 & 6 & 5 & 6 \\
\hline $\mathbf{E}_{\mathbf{2}}$ & 2 & 5 & 8 & 6 & 9 & 3 & 8 \\
\hline $\mathbf{E}_{\mathbf{3}}$ & 6 & 7 & 9 & 8 & 5 & 9 & 8 \\
\hline
\end{tabular}

Then, a standard matrix is given by using Equations (2) and (3) in Table 6.

Table 6. The standard matrix for the criteria set $\left(C_{1}\right)$.

\begin{tabular}{|l|c|c|c|c|c|c|c|}
\hline & $\mathbf{C}_{\mathbf{1 1}}$ & $\mathbf{C}_{\mathbf{1 2}}$ & $\mathbf{C}_{\mathbf{1 3}}$ & $\mathbf{C}_{\mathbf{1 4}}$ & $\mathbf{C}_{\mathbf{1 5}}$ & $\mathbf{C}_{\mathbf{1 6}}$ & $\mathbf{C}_{\mathbf{1 7}}$ \\
\hline $\mathbf{E}_{\mathbf{1}}$ & 0.4286 & 0.5025 & 0.5026 & 0.6690 & 0.5035 & 0.4663 & 0.4685 \\
\hline $\mathbf{E}_{\mathbf{2}}$ & 0.2857 & 0.5025 & 0.5744 & 0.4460 & 0.7553 & 0.2798 & 0.6247 \\
\hline $\mathbf{E}_{\mathbf{3}}$ & 0.8571 & 0.7035 & 0.6462 & 0.5946 & 0.4196 & 0.8393 & 0.6247 \\
\hline
\end{tabular}

By applying Equation (4), a set of the sub-criteria's weights $\left\{\mathrm{C}_{11}, \mathrm{C}_{12}, \mathrm{C}_{13}, \mathrm{C}_{14}, \mathrm{C}_{15}, \mathrm{C}_{16}, \mathrm{C}_{17}\right\}$ is found.

$$
a_{j}=(0.1903,0.1238,0.1180,0.1244,0.1371,0.1857,0.1206) .
$$

Then, we construct a weighted normalized decision matrix by applying Equation (5) in Table 7.

Table 7. The weighted normalized matrix for the criteria set $\left(\mathrm{C}_{1}\right)$.

\begin{tabular}{|c|c|c|c|c|c|c|c|}
\hline & $\mathbf{C}_{\mathbf{1 1}}$ & $\mathbf{C}_{\mathbf{1 2}}$ & $\mathbf{C}_{\mathbf{1 3}}$ & $\mathbf{C}_{\mathbf{1 4}}$ & $\mathbf{C}_{\mathbf{1 5}}$ & $\mathbf{C}_{\mathbf{1 6}}$ & $\mathbf{C}_{\mathbf{1 7}}$ \\
\hline $\mathbf{E}_{\mathbf{1}}$ & 0.0816 & 0.0622 & 0.0593 & 0.0832 & 0.0690 & 0.0866 & 0.0565 \\
\hline $\mathbf{E}_{\mathbf{2}}$ & 0.0544 & 0.0622 & 0.0678 & 0.0555 & 0.1035 & 0.0519 & 0.0754 \\
\hline $\mathbf{E}_{\mathbf{3}}$ & 0.1631 & 0.0871 & 0.0763 & 0.0740 & 0.0575 & 0.1558 & 0.0754 \\
\hline
\end{tabular}

Next, the vector pairs PIS (Positive Ideal Solution) and NIS (Negative Ideal Solution) are given by using Equations (6) and (7), we have the results of the PIS and NIS as follows.

$$
\begin{aligned}
& \boldsymbol{A}^{*}=(0.1631,0.0871,0.0763,0.0832,0.1035,0.1558,0.0754) . \\
& \boldsymbol{A}^{-}=(0.0544,0.0622,0.0593,0.0555,0.0575,0.0519,0.0565) .
\end{aligned}
$$

Thereafter, we calculated distances to ideal solutions based on Euclidean distance formula by handling Equations (8) and (9).

$$
\begin{aligned}
& \boldsymbol{S}^{*}=(0.0139,0.0241,0.0022) . \\
& \boldsymbol{S}^{-}=(0.0028,0.0025,0.0242) .
\end{aligned}
$$

Finally, a similar measure to the ideal solution is calculated by using Equation (10). We have the positive degree of the experts $\mathbf{E}_{\mathbf{1}}, \mathbf{E}_{\mathbf{2}}, \mathbf{E}_{\mathbf{3}}(0.1697,0.0955,0.9167$ respectively). This output result of the sub-criteria $\left\{\mathrm{C}_{11}, \mathrm{C}_{12}, \mathrm{C}_{13}, \mathrm{C}_{14}, \mathrm{C}_{15}, \mathrm{C}_{16}, \mathrm{C}_{17}\right\}$ will be gotten as the input of the criteria set $\mathbf{C}_{\mathbf{1}}$. Similarly, with the five remaining criteria sets $\left\{C_{2}, C_{3}, \ldots, C_{6}\right\}$, we gain a decision matrix for the criteria sets in Table 8 as follows. 
Table 8. The decision matrix for the criteria sets.

\begin{tabular}{|l|c|c|c|c|c|c|}
\hline & $\mathbf{C}_{\mathbf{1}}$ & $\mathbf{C}_{\mathbf{2}}$ & $\mathbf{C}_{\mathbf{3}}$ & $\mathbf{C}_{\mathbf{4}}$ & $\mathbf{C}_{\mathbf{5}}$ & $\mathbf{C}_{\mathbf{6}}$ \\
\hline $\mathbf{E}_{\mathbf{1}}$ & 0.1697 & 0.9301 & 0.1015 & 0.1811 & 0.9096 & 0.9235 \\
\hline $\mathbf{E}_{\mathbf{2}}$ & 0.0955 & 0.4063 & 0.9675 & 0.1595 & 0.3565 & 0.8807 \\
\hline $\mathbf{E}_{\mathbf{3}}$ & 0.9167 & 0.2890 & 0.5929 & 0.9976 & 0.6660 & 0.0765 \\
\hline
\end{tabular}

Step 2. Rank the level of the positive degree evaluations of the experts. By similar calculation as Step 1 for the criteria sets, we gain the level of the positive degree of the evaluation experts $\mathbf{E}_{\mathbf{1}}<$ $\mathbf{E}_{\mathbf{2}}<\mathbf{E}_{3}(0.2254<0.3011<0.7567)$. We easily recognize that if the result of the expert $\mathbf{E}_{3}$ is used, the final result will be gotten the best positive evaluation result. However, the best positive degree is not always the best. To give a reasonable selection with most of the experts, we should select the evaluation result of the expert $\mathbf{E}_{2}$ to estimate the effect of the criteria sets at the moderate level.

Step 3. Find the set of weights for experts by using fuzzy AHP. As mentioned, the evaluation result of the expert $\mathbf{E}_{2}$ in Table 9 is selected to establish the effect matrix among the criteria sets.

Table 9. The impact evaluation data among the criteria sets of the expert $\mathbf{E}_{2}$.

\begin{tabular}{|l|c|c|c|c|c|c|}
\hline & $\mathbf{C}_{\mathbf{1}}$ & $\mathbf{C}_{\mathbf{2}}$ & $\mathbf{C}_{\mathbf{3}}$ & $\mathbf{C}_{\mathbf{4}}$ & $\mathbf{C}_{\mathbf{5}}$ & $\mathbf{C}_{\mathbf{6}}$ \\
\hline $\mathbf{E}_{\mathbf{2}}$ & 0.0955 & 0.4063 & 0.9675 & 0.1595 & 0.3565 & 0.8807 \\
\hline
\end{tabular}

We conduct to convert the data in Table 9 into the compared matrix among the criteria sets in Table 10 by using Equation (11) as follows.

Table 10. The compared matrix among the criteria sets.

\begin{tabular}{|c|c|c|c|c|c|c|}
\hline & $\mathbf{C}_{\mathbf{1}}$ & $\mathbf{C}_{\mathbf{2}}$ & $\mathbf{C}_{\mathbf{3}}$ & $\mathbf{C}_{\mathbf{4}}$ & $\mathbf{C}_{\mathbf{5}}$ & $\mathbf{C}_{\mathbf{6}}$ \\
\hline $\mathbf{C}_{\mathbf{1}}$ & 1 & $1 / 4$ & $1 / 10$ & $1 / 2$ & $1 / 4$ & $1 / 9$ \\
\hline $\mathbf{C}_{\mathbf{2}}$ & 4 & 1 & $1 / 2$ & 3 & 1 & $1 / 2$ \\
\hline $\mathbf{C}_{\mathbf{3}}$ & 10 & 2 & 1 & 6 & 3 & 1 \\
\hline $\mathbf{C}_{\mathbf{4}}$ & 2 & $1 / 3$ & $1 / 6$ & 1 & $1 / 2$ & $1 / 6$ \\
\hline $\mathbf{C}_{\mathbf{5}}$ & 4 & 1 & $1 / 3$ & 2 & 1 & $1 / 2$ \\
\hline $\mathbf{C}_{\mathbf{6}}$ & 9 & 2 & 1 & 6 & 2 & 1 \\
\hline
\end{tabular}

An eigenvector of the compared matrix among the criteria sets is calculated.

$$
\mathrm{w}=(0.0333,0.1418,0.3376,0.0556,0.1244,0.3073) \text {. }
$$

Table 11. The set of weights for the evaluation experts.

\begin{tabular}{|c|c|c|c|c|c|c|c|}
\hline & $\mathbf{C}_{\mathbf{1}}$ & $\mathbf{C}_{\mathbf{2}}$ & $\mathbf{C}_{\mathbf{3}}$ & $\mathbf{C}_{\mathbf{4}}$ & $\mathbf{C}_{\mathbf{5}}$ & $\mathbf{C}_{\mathbf{6}}$ & $\mathbf{W}$ \\
\hline $\mathbf{E}_{\mathbf{1}}$ & 0.5813 & 0.6270 & 0.6405 & 0.5467 & 0.3201 & 0.2992 & 0.4867 \\
\hline $\mathbf{E}_{\mathbf{2}}$ & 0.3092 & 0.2923 & 0.2059 & 0.3844 & 0.1497 & 0.3452 & 0.2673 \\
\hline $\mathbf{E}_{\mathbf{3}}$ & 0.1096 & 0.0807 & 0.1537 & 0.0689 & 0.5302 & 0.3555 & 0.2460 \\
\hline $\mathbf{W}$ & 0.0333 & 0.1418 & 0.3376 & 0.0556 & 0.1244 & 0.3073 & 1.0000 \\
\hline
\end{tabular}

By applying AHP, the eigenvectors of the criteria sets are also calculated based on the scale of the criteria set importance in Table 4 . We then find the set of weights for the evaluation experts in Table 11 . 
Step 4. Find the criteria's PFS and calculate the fuzzy decision point of the policy. From the information in Table 5, we get the sub-criteria's PFS of the criteria set $\mathrm{C}_{1}$ by applying Equations (12), (13), (14), and (15). The detailed results are expressed in Table 12.

Table 12. The sub-criteria's PFS of the criteria set $\mathbf{C}_{1}$.

\begin{tabular}{|c|c|c|c|c|c|c|}
\hline $\mathbf{C}_{\mathbf{1 1}}$ & $\mathbf{C}_{\mathbf{1 2}}$ & $\mathbf{C}_{\mathbf{1 3}}$ & $\mathbf{C}_{\mathbf{1 4}}$ & $\mathbf{C}_{\mathbf{1 5}}$ & $\mathbf{C}_{\mathbf{1 6}}$ & $\mathbf{C}_{\mathbf{1 7}}$ \\
\hline$(0,0,0.5)$ & $(0,1,0)$ & $(0.5,0,0)$ & $(1,0,0)$ & $(0.25,0.5,0)$ & $(0,1,0)$ & $(0.25,0.5,0)$ \\
\hline$(0,0,0.75)$ & $(0,1,0)$ & $(0.75,0,0)$ & $(0.25,0.5,0)$ & $(1,0,0)$ & $(0,0,0.5)$ & $(0.75,0,0)$ \\
\hline$(0.25,0.5,0)$ & $(0.5,0,0)$ & $(1,0,0)$ & $(0.75,0,0)$ & $(0,1,0)$ & $(1,0,0)$ & $(0.75,0,0)$ \\
\hline
\end{tabular}

By using Equations (16) and (17), we find the PFS of the criteria set $\mathbf{C}_{\mathbf{1}}$.

$$
P_{C_{1}}=(0.39,0.32,0.08) \text {. }
$$

Similarly, we get the PFS of the criteria sets in Table 13 below.

Table 13. The PFS of the criteria sets.

\begin{tabular}{|c|c|c|c|c|c|}
\hline $\boldsymbol{P}_{\boldsymbol{C}_{1}}$ & $\boldsymbol{P}_{\boldsymbol{C}_{2}}$ & $\boldsymbol{P}_{\boldsymbol{C}_{3}}$ & $\boldsymbol{P}_{\boldsymbol{C}_{4}}$ & $\boldsymbol{P}_{\boldsymbol{C}_{5}}$ & $\boldsymbol{P}_{\boldsymbol{C}_{6}}$ \\
\hline$(0.39,0.32,0.08)$ & $(0.29,0.29,0.17)$ & $(0.32,0.28,0.16)$ & $(0.36,0.29,0.12)$ & $(0.45,0.22,0.06)$ & $(0.36,0.41,0.02)$ \\
\hline
\end{tabular}

We calculate the final PFS of the policy with the set of the expert's weight by using Equations (16) and (17).

$$
P=(0.36,0.30,0.10) \text {. }
$$

Finally, we get the fuzzy decision point of the policy $S_{P}=0.3231$ by applying Equation (18). From the rating scale of the policy's quality, we have the evaluation threshold for the policy by using PFS in Table 14 as follows. Therefore, with this evaluation result, the proposed policy is evaluated at the "Quite Good" level.

Table 14. The evaluation threshold for the policy's quality.

\begin{tabular}{|c|c|c|}
\hline Order & Evaluation threshold & Policy's quality \\
\hline 1 & $S_{P} \geq 1$ & Very Good \\
\hline 2 & $0.75 \leq S_{P}<1$ & Good \\
\hline 3 & $0 \leq S_{P}<0.75$ & Quite Good \\
\hline 4 & $-0.75 \leq S_{P}<0$ & Normal \\
\hline 5 & $-1 \leq S_{P}<-0.75$ & Bad \\
\hline 6 & $S_{P}<-1$ & Very Bad \\
\hline
\end{tabular}

\section{Experimental Results}

\subsection{Experimental Environments}

In this part, we present the experiments' results to validate the proposed method in the real world. One of the problems is selected to do the experiments based on the indicator groups in the final urban development project of the Ministry of Construction in December 2019. The proposed method has been tested in simulations with ten experts (various majors) $\left\{E_{1}, E_{2}, E_{3}, E_{4}, E_{5}, E_{6}, E_{7}, E_{8}, E_{9}, E_{10}\right\}$ to vote for urban development policies in the construction sector. In the experiment, we have tested the proposed model to show the advancement approach by using the PFS combined with the TOPSIS- 
AHP. The list of national urban development database indicators has six groups of indicators, representing six groups of information with 47 indicators in policymaking of an urban development database system in Table 15 as follows. We have designed simulation scenarios based on collected data of the three cities in Vietnam (including Hai Phong, Da Nang, Can Tho) from January 2020 to April 2021. The evaluation result is conducted at the beginning of the phase (in January 2020) and after every quarter.

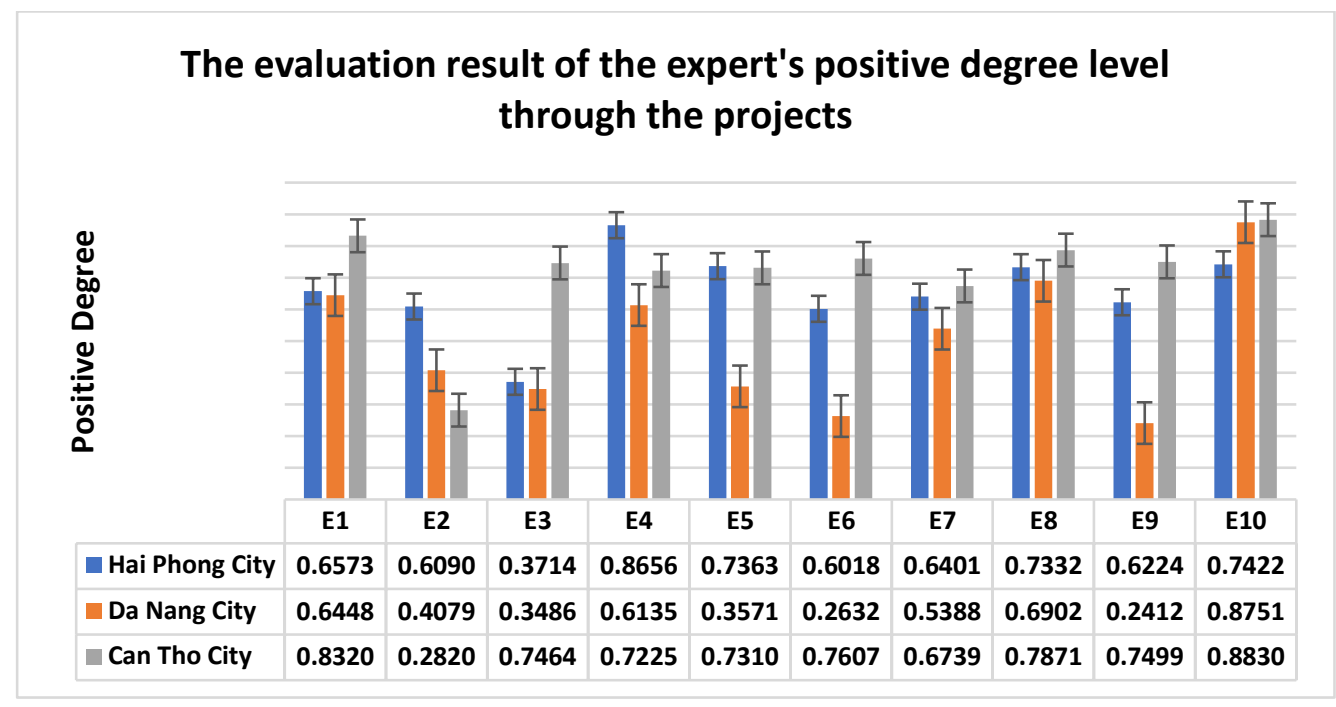

Figure 3. The evaluation result of the expert's positive degree.

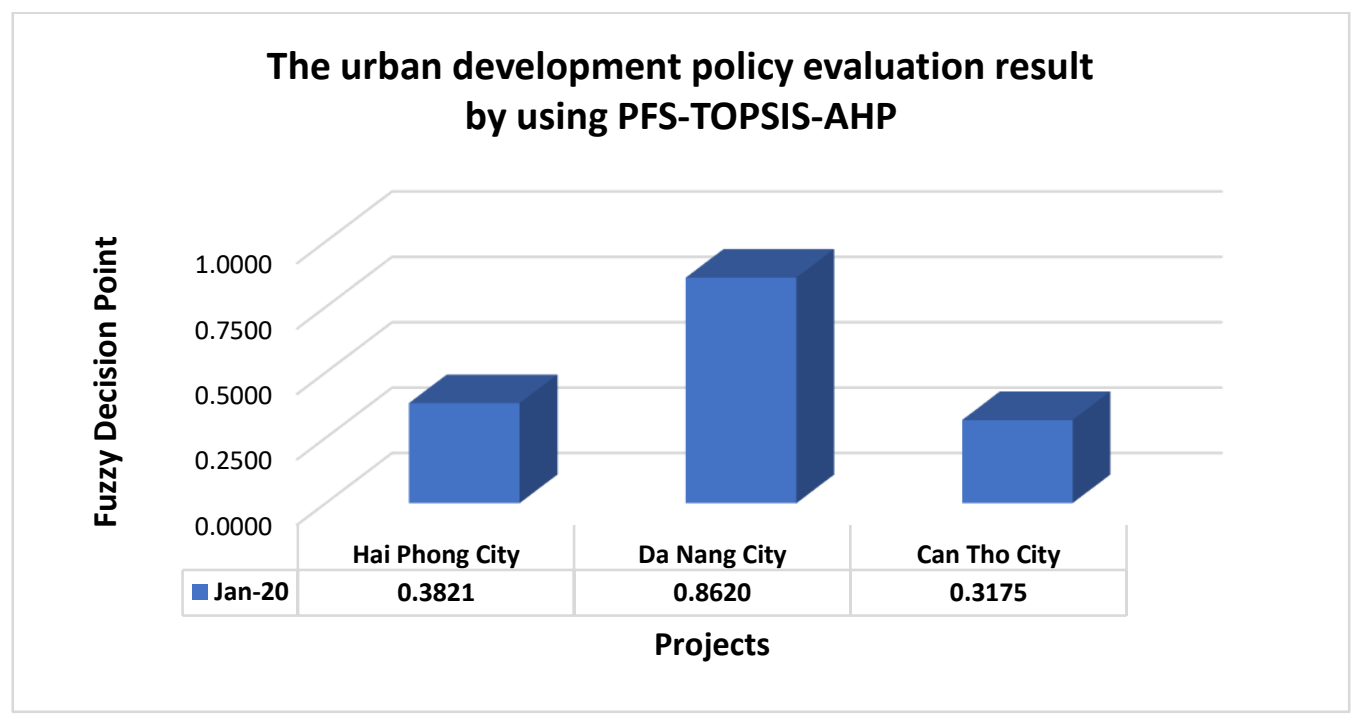

Figure 4. The urban development policy evaluation result by using PFS-TOPSIS-AHP model.

\subsection{Results and Discussions}

Firstly, the proposed model is applied to give the evaluation result of the expert's positive degree. 
Figure 3 shows that the expert $\left(\mathrm{E}_{10}\right)$ has the best positive degree level (approximation 0.8334 on average) while the lowest positive degree expert is $E_{2}$ ( 0.4329 on average). This result helps the decision-maker to identify the experts who have the higher positive degree evaluation level to recommend for the next evaluations.

Table 15. The list of national urban development database indicators.

\begin{tabular}{|c|c|}
\hline Indicator Groups & Indicators \\
\hline Group 1 (Urbanization) & $\begin{array}{ll}\text { - } & \text { Urban type/Classification year } \\
\text { - } & \text { Latest approved general planning for urban development (year of approval) } \\
\text { - } & \text { Population of the inner city }(1000 \text { people) } \\
\text { - } & \text { Population density of the inner city (people/km2) } \\
\text { - } & \text { Population density of the entire city (people/km2) } \\
\text { - } & \text { Female proportion in the urban population }(\%) \\
\text { - } & \text { Land area of the entire city }(\mathrm{km} 2) \\
\text { - } & \text { Land area of the inner city }(\mathrm{km} 2) \\
\text { - } & \text { Land area for urban construction (calculated according to plan) }(\mathrm{km} 2) \\
\text { - } & \text { Transportation land area on total urban population }(\mathrm{m} 2 / \text { person }) \\
\text { - } & \text { Transportation land area on inner-city population }(\mathrm{m} 2 / \text { person) } \\
\end{array}$ \\
\hline Group 2 (Income and poverty) & 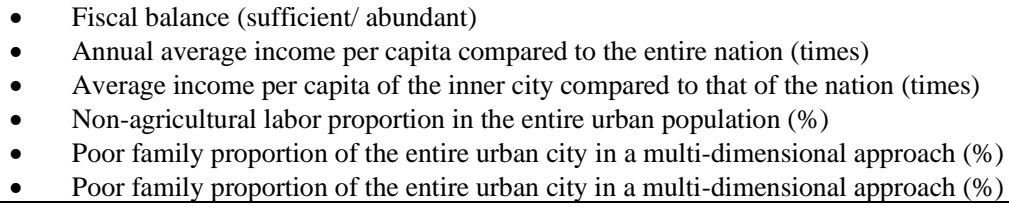 \\
\hline Group 3 (Social infrastructure) & 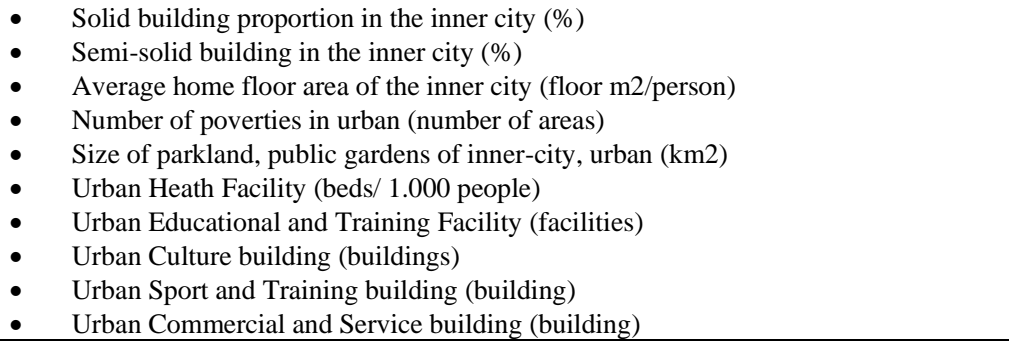 \\
\hline Group 4 (Technical infrastructure) & $\begin{array}{l}\text { - } \quad \text { Traffic road density (up to a width } \geq 7.5 \mathrm{~m} \text { of vehicles section) }(\mathrm{km} / \mathrm{km} 2) \\
\text { - } \\
\text { - } \\
\text { - }\end{array}$ \\
\hline $\begin{array}{c}\text { Group } 5 \text { (Environment quality and } \\
\text { climate change) }\end{array}$ & $\begin{array}{l}\text { - } \\
\text { Ratio of life solid waste collected }(\%) \\
\text { Ratio of life solid waste treated } \\
\text { - } \\
\text { - } \\
\text { Prban has developed an action plan to cope with climate change (annually) (yes/no) } \\
\text { (points) } \\
\text { Days of water loss in the year due to droughts, flooding (days) }\end{array}$ \\
\hline $\begin{array}{c}\text { Group } 6 \text { (Investment and urban } \\
\text { administration) }\end{array}$ & $\begin{array}{ll}\text { - } & \text { Total investment for urban construction (billion VND/year) } \\
\text { - } & \text { Number of deploying urban development projects (quantity) } \\
\text { - } & \text { Urban development programs approved (yes/no) } \\
\text { - } & \text { Ratio of the publicly administrative procedures on the website of urban authorities }\end{array}$ \\
\hline
\end{tabular}


Secondly, the evaluation result of the projects is given by applying the PFS-TOPSIS-AHP model in Figure 4. From the rating scale for the policy's quality evaluation given in Table 14 and the project evaluation result in Figure 4, we can see that the policy of Da Nang city is evaluated at the "Good" level while the policies of the remaining cities are "Quite Good" level. This information gives assistance to the decision-maker to know the quality of the new policy before promulgating it.

Finally, the evaluation results every quarter are given by using the PFS-TOPSIS-AHP model to validate the quality of the projects when they are affected by newly enacted laws. Figure 5 shows that the fuzzy decision point of the projects varied slightly for all projects (less than 10\%) when the weights of the indicator groups are adjusted following the new laws. This demonstrates that the evaluation quality of the projects by applying the proposed method is assured even in case some new laws are promulgated.

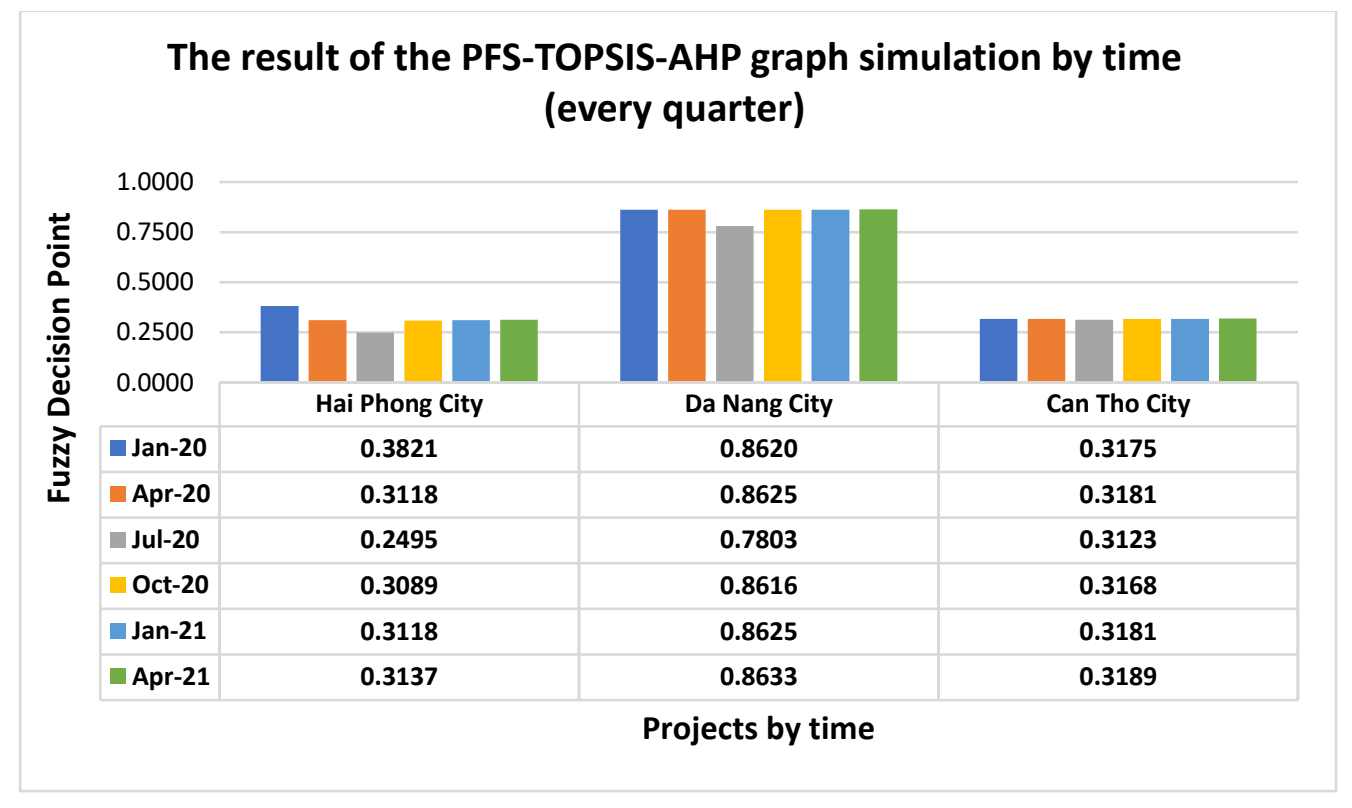

Figure 5. The evaluation result of projects by time (every quarter).

\section{Conclusions}

This paper proposed the novel proposed model for GDM by integrating the PFS technique into the TOPSIS-AHP method (shortly PFS-TOPSIS-AHP model). The proposed model quantified both qualitative and quantitative factors to evaluate the policies to make complex decisions under uncertainty. It is considered as an initial work to evaluate the policy's quality under a dynamic environment via the fuzzy decision point by applying the PFS technique in the real world. Furthermore, the experimental result shows the proposed method based on the indicator groups in the final urban development project of the Ministry of Construction in Vietnam combined with the expert's expertise and the decision maker's preference to give the evaluation result of newly enacted policy quality more confidence compared to the state-of-the-art works.

Further works are identified to recommend for researchers and developers in the future: (1) studying how to quantify the input value as a matrix instead of a numerical or vector value for the proposed 
model when data sets are images or spatial data; (2) deploying the software to quantify the vague value by applying PFS technique to calculate automatically the fuzzy decision point of the policy; (3) investigating the combination of both: qualitative and quantitative factors; weighted normalization methods and scaling techniques; calculated measures-based decision-makers and preferences-based decision-makers.

\section{Conflict of Interest}

There are no potential conflicts here anyway.

\section{Acknowledgments}

This research is funded by the Ministry of Education and Training in Vietnam under grant Number: CT2020.02.BKA.07. The authors would like to thank greatly Reviewers and Editors who gave valuable comments for this manuscript to improve it before publication.

\section{References}

Akram, M., Naz, S., Edalatpanah, S.A., \& Mahreen, R. (2021). Group decision-making framework under linguistic q-rung orthopair fuzzy Einstein models. Soft Computing, 25, 10309-10334.

Cuong, B.C. (2014). Picture fuzzy sets. Journal of Computer Science and Cybernetics, 30(4), 409-420.

de Farias Aires, R.F., \& Ferreira, L. (2019). A new approach to avoid rank reversal cases in the TOPSIS method. Computers \& Industrial Engineering, 132, 84-97.

Djenadic, S., Ignjatovic, D., Tanasijevic, M., Bugaric, U., Jankovic, I., \& Subaranovic, T. (2019). Development of the availability concept by using fuzzy theory with AHP correction, a case study: bulldozers in the open-pit lignite mine. Energies, 12(21), 1-18.

Edalatpanah, S.A. (2020). Neutrosophic structured element. Expert Systems, 37(5), e12542. https://doi.org/10.1111/exsy.12542.

Garg, H., Sujatha, R., Nagarajan, D., Kavikumar, J., \& Gwak, J. (2021). Evidence theory in picture fuzzy set environment. Journal of Mathematics, 2021, 1-8.

Hai, P.V., \& Esichaikul, V. (2008). A web-based decision support system for the evaluation and strategic planning using ISO 9000 factors in higher education. VNU Journal of Science, Mathematics-Physics, 24, 197-208.

Kahraman, C., Öztayşi, B., \& Onar, S.C. (2018). An integrated intuitionistic fuzzy AHP and TOPSIS approach to evaluation of outsource manufacturers. Journal of Intelligent Systems, 29(1), 283-297.

Kara, Y. (2019). Measuring the sustainability of cities in Turkey with the analytic hierarchy process. Open Journal of Social Sciences, 7(4), 322-334.

Kaya, I., Colak, M., \& Terzi, F. (2019). A comprehensive review of fuzzy multi criteria decision making methodologies for energy policy making. Energy Strategy Reviews, 24, 207-228.

Khan, M.J., Kumam, P., Deebani, W., Kumam, W., \& Shah, Z. (2020). Bi-parametric distance and similarity measures of picture fuzzy sets and their applications in medical diagnosis. Egyptian Informatics Journal, 22(2), 201-212.

Lan, L.T.H., Tuan, T.M., Ngan, T.T., Son, L.H., Giang, N.L., Ngoc, V.T.N., \& Hai, P.V. (2020). A new complex fuzzy inference system with fuzzy knowledge graph and extensions in decision making. IEEE Access, 8, 164899-164921. 
Liu, Y., Eckert, C.M., \& Earl, C. (2020). A review of fuzzy AHP methods for decision-making with subjective judgments. Expert Systems with Applications, 161, 113738.

Long, C.K., Agrawal, R., Trung, H.Q., \& Hai, P.V. (2021). A big data framework for e-government in industry 4.0. Open Computer Science 11(1), 461-479.

Munro, F.R., \& Cairney, P. (2020). A systematic review of energy systems: The role of policymaking in sustainable transitions. Renewable and Sustainable Energy Reviews, 119, 1-10.

Munro, F.R., \& Cairney, P. (2020). A systematic review of energy systems: The role of policymaking in sustainable transitions. Renewable and Sustainable Energy Reviews, 119, 109598.

Moore, P., \& Pham, H.V. (2012). Intelligent context with decision support under uncertainty. In 2012 Sixth International Conference on Complex, Intelligent, and Software Intensive Systems (pp. 977-982). IEEE. Palermo, Italy.

Pluchinotta, I., Esposito, D., \& Camarda, D. (2019). Fuzzy cognitive mapping to support multi-agent decisions in development of urban policymaking. Sustainable Cities and Society, 46, 101402.

Salih, M.M., Zaidan, B.B., Zaidan, A.A., \& Ahmed, M.A. (2019). Survey on fuzzy TOPSIS state-of-the-art between 2007 and 2017. Computers \& Operations Research, 104, 207-227.

Salimi, P.S., \& Edalatpanah, S.A. (2020). Supplier selection using fuzzy ahp method and d-numbers. Journal of Fuzzy Extension and Application, 1(1), 1-14.

Si, A., Das, S., \& Kar, S. (2021). Picture fuzzy set-based decision-making approach using Dempster-Shafer theory of evidence and grey relation analysis and its application in COVID-19 medicine selection. Soft Computing, 1-15.

Sirbiladze, G. (2021). New view of fuzzy aggregations. Part I: general information structure for decisionmaking models title. Journal of Fuzzy Extension and Application, 2(2), 130-143.

Son, L.H., Viet, P.V., \& Hai, P.V. (2016). Picture inference system: a new fuzzy inference system on picture fuzzy set. Applied Intelligence, 46(3), 652-669.

Tang, M., \& Liao, H. (2019). From conventional group decision making to large-scale group decision making: What are the challenges and how to meet them in big data era? A state-of-the-art survey. Omega, 100, 102141.

Zadeh, L.A. (1965). Information and control. Fuzzy Sets, 8, 338-353.

Zaidan, A.A., Zaidan, B.B., Al-Haiqi, A., Kiah, M.L.M., Hussain, M., \& Abdulnabi, M. (2015). Evaluation and selection of open-source EMR software packages based on integrated AHP and TOPSIS. Journal of Biomedical Informatics, 53, 390-404. 